\title{
Drying-up of a natural spring for ensuring stability of an artificial slope: is it sustainable development?
}

\author{
Marie Dachy ${ }^{1}$, Sandrine Sage ${ }^{2} \&$ Alain Dassargues ${ }^{1,3}$ \\ ${ }^{1}$ Hydrogeology \& Environmental Geology, Dpt Georesources, Geotechnologies and Building \\ Materials (GeomaC), University of Liège \\ ${ }^{2}$ Geophysical Prospecting, Dpt Georesources, Geotechnologies and Building Materials \\ (GeomaC), University of Liège \\ ${ }^{3}$ Hydrogeology \& Engineering Geology, Dpt Geology-Geography, KULeuven
}

Email:_Marie.Dachy@ulg.ac.be

Tel: 04 / 366.23.58

Fax: 04 / 366.95.20

KEYWORDS: hydrogeology, geoelectrical tomography, impact of drainage, drying up a natural spring

\begin{abstract}
Near a small city of the Belgian 'Ardennes' (East of Belgium), modification of a natural slope for extension of industrial activities has required an extensive drainage in a weathered zone composed of colluvium and weathered claystones and quartzites. After a few days, the drain at the foot of the artificial slope was producing about $1000 \mathrm{~m}^{3} /$ day while a natural spring located at a $200 \mathrm{~m}$ distance on the hillside was completely dried up. This spring was used for drinking water by the local community. A shallow geophysical prospection by refraction seismics and 2D geoelectrical tomography, associated to geological, morphostructural and hydrogeological observations have lead to a clear understanding of (1) the spring occurrence; (2) the feeding conditions of the spring and consequently (3) the 'lateral' hydraulic impact of the drain. In the hill, the bedrock is changing from quartzites (uphill) to claystones (downhill) inducing changes in hydraulic conductivity and thickness of the overlying weathered zone. On the basis of these hydrogeological conditions, associated to the specific topographic conditions, different possible remediation schemas have been proposed to the decision makers. Unfortunately, the full restoration of the natural spring appears to be one of the most technically and financially difficult option .... while it is surely the most suitable in the name of a sustainable development.
\end{abstract}

\section{INTRODUCTION}

In order to create an horizontal platform for extension of its industrial activities, a private company has received the authorization to modify the natural slope of a hillside. The local geology of the area consists of quartzitic rocks and schists belonging to lower Salmian age (Cambrian). The direction of the layers is more or less parallel to the direction of the valley (SW-NE) with a dip towards the south. The schematic SE-NW cross-section of figure 1 illustrates the relation between geomorphology and geology in this region. Quartzites are generally observed at the top and higher parts of the hills while schists are found back in the lower parts of the valleys. Usually, in that region, the transition zone between quartzites and 
schists is observed to be relatively sharp. Here, however, the hillslope seems uniform, not showing any clear transition zone. Works of extension of the company required an earthwork platform. Topographically, the ground surface, originally inclined towards NW, has been transformed for presenting a platform at the absolute level of $417 \mathrm{~m}$, the top of the remaining slope being at $428 \mathrm{~m}$ (figure 2). However, very soon, groundwater seepage from the reshaped slope was observed. It was also threatening the slope stability. A drain was placed at the base of the slope, along the entire width of the extension zone. The base of the drain is at the absolute level of $415 \mathrm{~m}$. This drain presents a slope of $0.5 \%$ and the water is collected east of the site. After a few days, the approximated daily water drained flow rate reached a value of $1000 \mathrm{~m}^{3} /$ day.

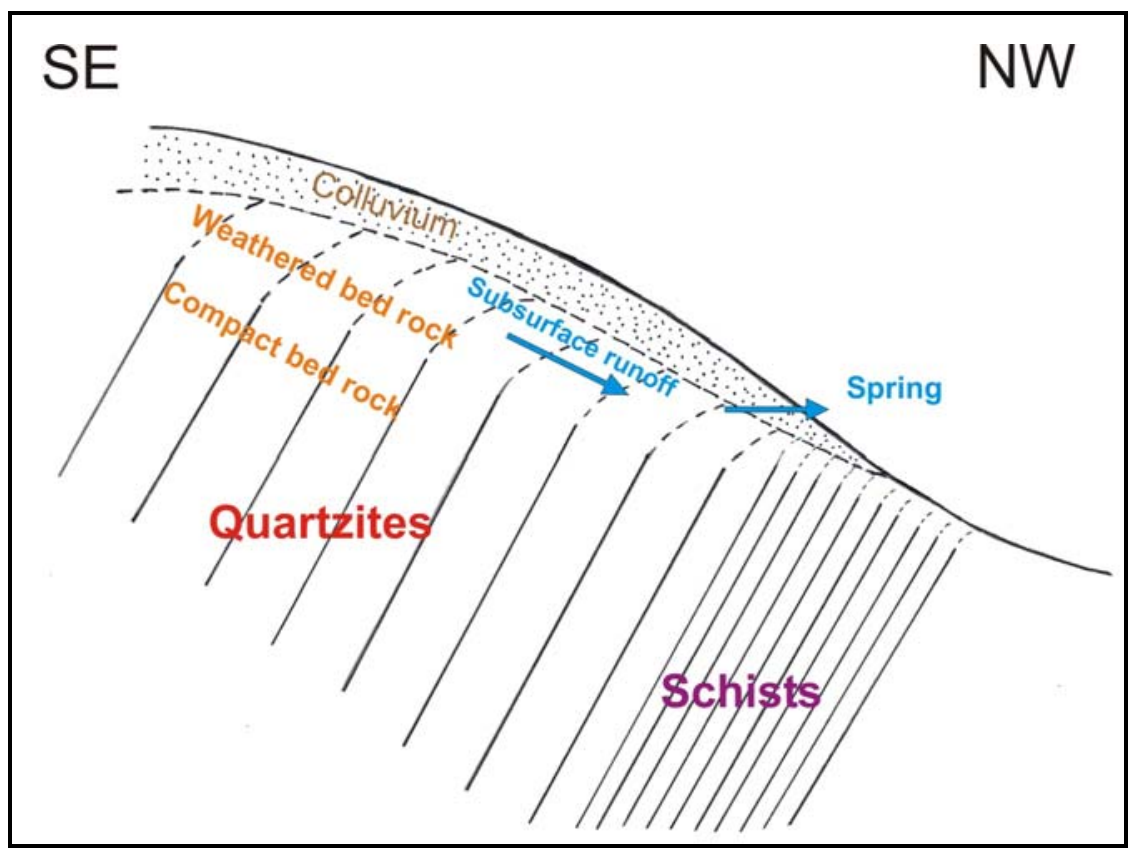

Figure 1. Schematic SE-NW geological cross-section normal to the layer direction and transverse to the valley. 


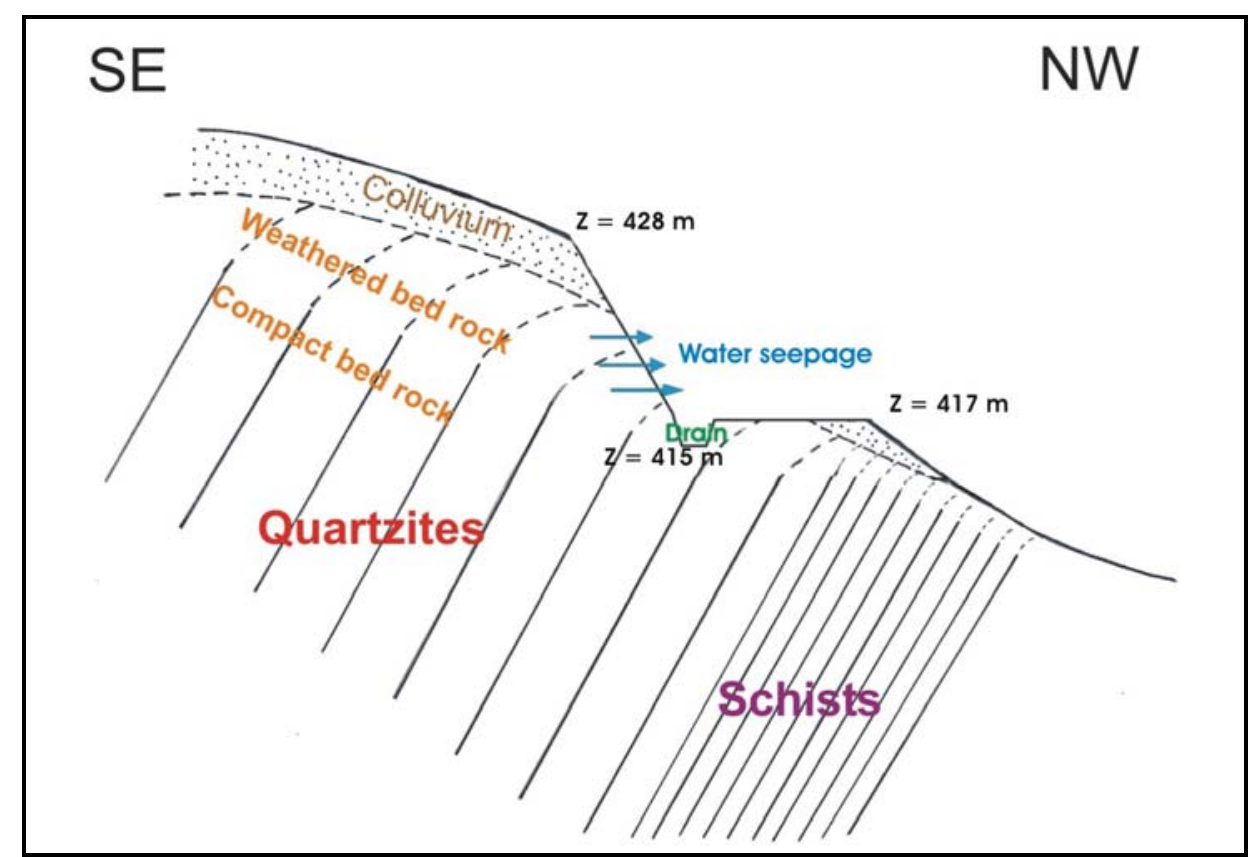

Figure 2. Schematic SE-NW transverse cross-section showing the reshaped slope and the position of the drain.

At the same time, the flow rate of a natural spring, located at a lateral distance of about $200 \mathrm{~m}$ from the drain on the same hillslope, brutally dropped and the spring eventually completely dried up. Previously, the averaged daily flow rate was comprised between $200 \mathrm{~m}^{3} /$ day and 350 $\mathrm{m}^{3} /$ day. The emergence of this spring was flowing at an absolute level of $422 \mathrm{~m}$. Another spring is emerging further on the same hillslope at a distance of more or less 1 kilometer and at the absolute level of $405 \mathrm{~m}$. The averaged daily flow rate of this last spring changed from $1330 \mathrm{~m}^{3}$ /day to $1036 \mathrm{~m}^{3} /$ day in fourteen days. Both of these springs were exploited by the local community for drinking water. A study was needed to determine the local hydrogeological context explaining the impact of the new drainage on the springs and to propose, if possible, sustainable alternatives.

\section{ANALYSING AND INVESTIGATING HYDROGEOLOGICAL CONDITIONS}

On the basis of the geological conditions indicated on the transverse cross-sections of figures $1 \& 2$, a crucial issue consists in accurately determining where the bedrock lithology changes from quarzites to schists. This matter is actually very important because of its considerable impact on the local colluvium characteristics. The weathering of quartzites mainly produces a sandy colluvium with relatively high hydraulic conductivity. This permeable mantle makes the water infiltration easier and thus allows further weathering and decomposition of the underlying quartzites. This process generates a relatively thick and permeable unit composed of weathered bedrock and colluvium. On the other hand, it is expected that the weathering and decomposition of the schists provide a more clayey colluvium. The low hydraulic conductivity of this layer does not favour deeper weathering and decomposition of the bedrock, thus resulting in a thin and relatively low permeability colluvium overlying the argillaceous schists bedrock. 
Within the sandy weathered bedrock and colluvium an important groundwater flow is possible. Considering that the slope of the valley is relatively long, the quantity of groundwater accumulated in the weathered bedrock and colluvium is significant. The presence of springs along the slope is most likely explained by the appearance of clays derived from the decomposition of the underlying schists. This change in permeability associated with a reduced thickness induces the emergence of groundwater at the surface. This change in the colluvium could normally provide indication on the contact between the quarzites and schists. However, a possible creep effect must also be considered. Examination of the topographic maps shows an alignment of the sources in that area along the hillslope between levels $400 \mathrm{~m}$ and $425 \mathrm{~m}$. Among the possible causes of the drying up, the abnormally dry climate conditions of this beginning of year 2003 were evoked. However, the history of the gaugings showed that the nearest spring was never dried up in the past, even at the time of the 1976 drought, and that its flow rate was never below $190 \mathrm{~m}^{3} /$ day. Moreover, the drying up of the nearest spring and the flow rate decay of the spring located $1 \mathrm{~km}$ further were observed shortly after the installation of the litigious drain. There was no other civil engineering work undertaken in the area at that time.

It thus clearly appears that the drying up of the nearest spring results from the installation of the drain within the weathered bedrock and colluvium in the extension zone of the company. Indeed, if the conceptual hydrogeological schema presented hereabove prevails in this hillslope, the drain and the spring are both supplied with the shallow groundwater flow which was at the origin in the SE-NW direction. The drain being at a $200 \mathrm{~m}$ distance from the spring, but at a lower absolute level (base of the drain at $415 \mathrm{~m}$, spring at $422 \mathrm{~m}$ ), it makes it possible for the groundwater to be drained at a considerable flow rate $\left(1000 \mathrm{~m}^{3} /\right.$ day $)$. This new exit point must probably influence the local water table and the groundwater streamlines towards the drain. A local water table lower than the spring level $(415 \mathrm{~m})$ caused the drying up of the nearest source. However, the lowering of the water table is probably sufficiently laterally limited to induce a flow rate decay of only $30 \%$ at the spring located about $1 \mathrm{~km}$ further.

\section{GROUNDWATER QUALITY AS AN INDICATOR OF A SHALLOW GROUNDWATER SYSTEM}

In terms of hydrochemistry, temporal evolution of the in situ measured $\mathrm{pH}$, temperature and conductivity showed an average $\mathrm{pH}$ of 6.07 at the nearest spring (before drying up). This slightly acid $\mathrm{pH}$ value is current in that region of the Ardennes. Average conductivity is of $73.16 \mu \mathrm{S} / \mathrm{cm}\left(20^{\circ} \mathrm{C}\right)$, which is characteristic of a groundwater with low mineralization. The seasonal fluctuations of the temperature (more than $6^{\circ}$ between $9{ }^{\circ} \mathrm{C}$ and $16{ }^{\circ} \mathrm{C}$ ) on the one hand and the weak mineralization, on the other hand, indicate that the spring is fed primarily by a shallow groundwater system. This observation is fully consistent with the conceptual hydrogeological schema described here above. The second spring located $1 \mathrm{~km}$ further has an average $\mathrm{pH}$ of 6.06 and an average conductivity of $92.35 \mu \mathrm{S} / \mathrm{cm}\left(20^{\circ} \mathrm{C}\right)$. The average temperature is of $10.54{ }^{\circ} \mathrm{C}$ fluctuating in the same way as for the other spring (maximum of $17^{\circ} \mathrm{C}$ reached in summer). The temperature fluctuations and the weak mineralisation also indicate a relatively short and shallow groundwater flow path. Results of the hydrochemical 
analysis performed for the drained water and for the water at the remaining spring, are illustrated in the Piper diagram of figure 3.

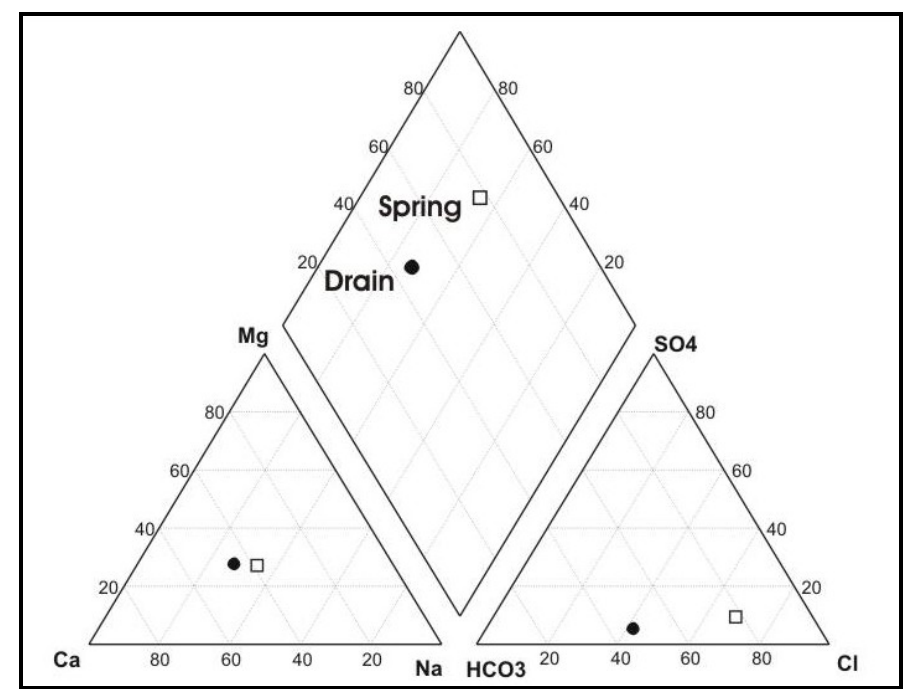

Figure 3. Piper diagram showing the relative hydrochemical characteristics of the groundwater in the drain and in the spring located $1 \mathrm{~km}$ further.

\section{SHALLOW GEOPHYSICAL PROSPECTING}

An hydrogeological model was proposed to explain the drying up of the nearest spring. A shallow geophysical study was proposed in order (1) to confirm the location of the bedrock lithological change from quarzites to schists, implying possible changes in the weathered bedrock and colluvium; (2) to determine the thickness of this colluvium and weathered zone overlying the bedrock (with an anticipated maximum thickness of about $10 \mathrm{~m}$ ). Refraction seismic and electric profiling were selected. The electric profiles are used in order to determine lithological changes resulting in different resistivities. The resistivity of quarzites is higher than that of schists. An electric profile with a 'dipole-dipole' or 'pole-dipole' configuration is usually able to detect lateral in-depth resistivity differences along a profile. The seismic refraction is currently used to detect the interface between the loose sediments and the bedrock. This method is used here to determine the thickness of the loose materials (weathered bedrock + colluvium) overlying the bedrock. Seismic velocity in the basement is indeed higher than in the overlying materials. A seismic profile was carried out along the hillside and two electric profiles were carried out along the slope : the first electric profile was close to the dried spring and the second one was close to the drain. Results are given in figure 4. 


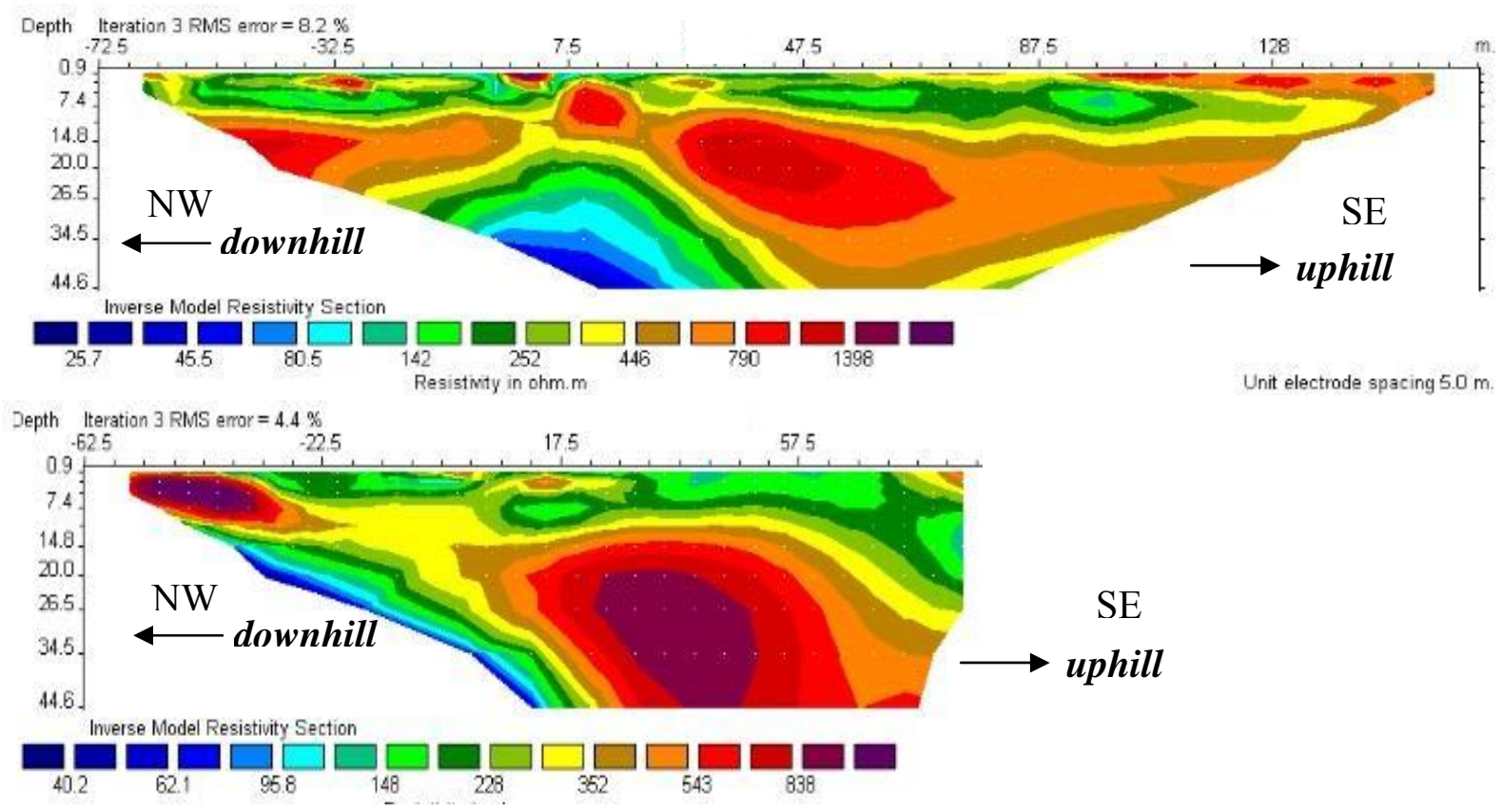

Figure 4. Modelled resistivity profiles near the dried spring (top) and near the drain (bottom).

On the first profile, a first horizon is characterized by apparent resistivities ranging between $100 \Omega \mathrm{m}$ and $300 \Omega \mathrm{m}$. It corresponds to an unconsolidated layer. This unit is thicker uphill and a local thinning is observed very close to the dried spring in the hillslope : a bed of very resistive rock, probably quartzitic, is nearly outcropping. The incomplete second profile only investigates the downhill part of the slope. Nevertheless, both profiles seem to indicate a lithological change from a resistive material uphill to a conductive material downhill. From the seismic results, a longitudinal (along the hillside) cross-section can be interpreted as shown on figure 5. A first layer of unconsolidated granular material having a maximum thickness of $2 \mathrm{~m}$ is overlying a second layer that can be identified as a weathered bedrock. The interface between this weathered zone and the bedrock seems very irregular and globally describes a thickening in the direction of the drain. 


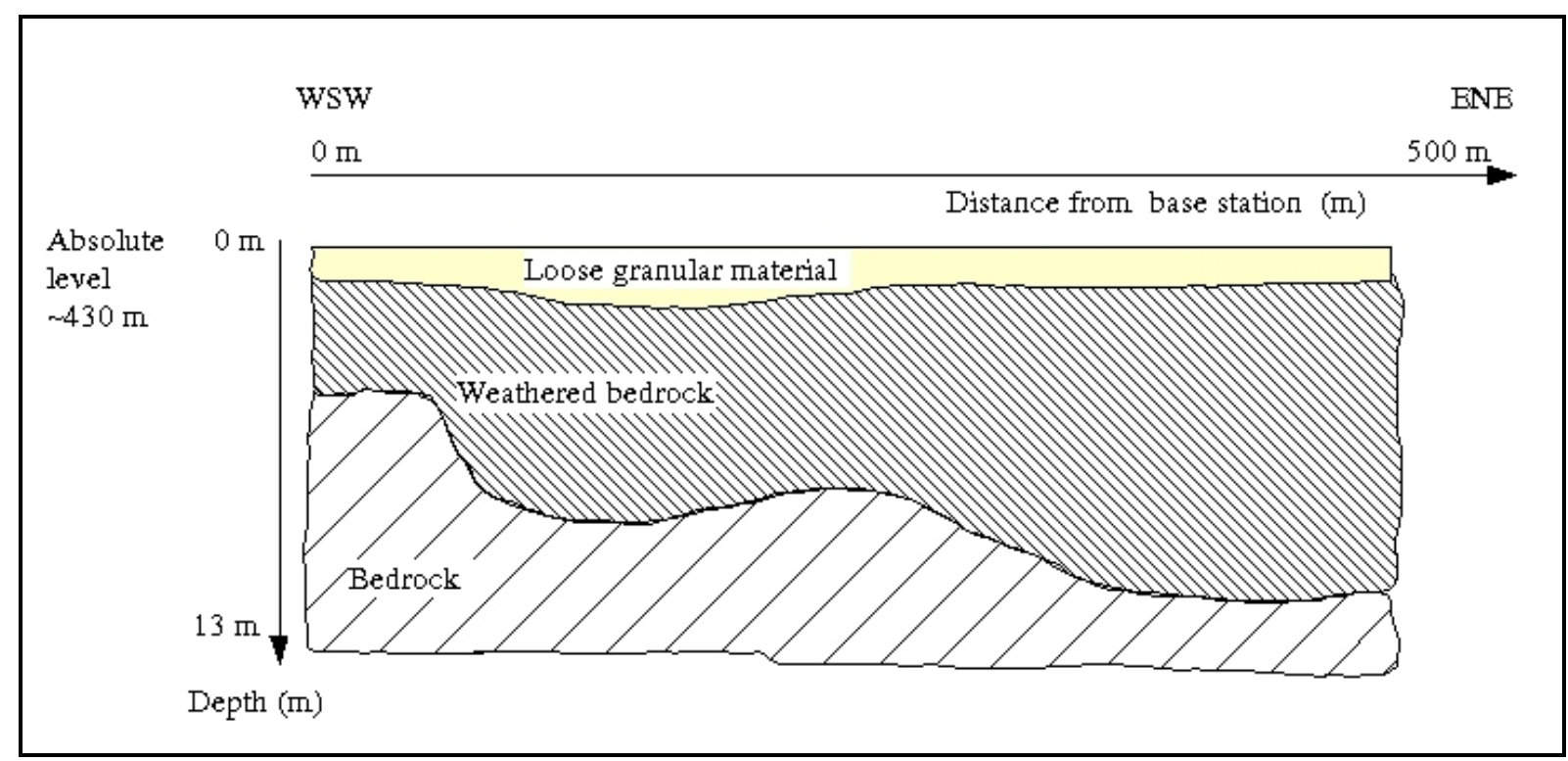

Figure 5. Interpretative profile from seismic results: a thickening of the weathered bed-rock is observed from the dried spring to the drain

\section{SUMMARY, CONCLUSIONS AND PERSPECTIVES}

The various investigations indicate that the constructed drain induces the drainage of a shallow groundwater system mainly included in the colluvium and the weathered bedrock overlying a Primary bedrock composed of quartzites changing downhill to schists. The geophysical prospection results have highlighted the presence of a quartzite bed nearly outcropping close to the dried spring. The presence of the spring would thus be related to a local thinning of the weathered bedrock which is the main aquifer layer. Additionnaly, less resistive materials appear downhill on the electric profiles. This resistivity change could be related to the change from quarzites to schists. The excavation of the platform and the drain at a very short distance from the spring, especially at an absolute level located $7 \mathrm{~m}$ below the outlet of the spring, caused the drainage of the saturated zone within the weathered bedrock. The induced drawdown is such that now the spring is completely dried up and located above the saturated zone. Unfortunately, the definitive conclusion is that the construction of the drain obviously has a disastrous impact on the spring feeding system. On the basis of these conclusions and considering the specific topographic conditions, different possible remediation schemas have been proposed to the decision makers.

a) Being given that the company does not plan to exploit the totality of the water volume tapped by the drain, a first solution could be to use the drain itself for producing drinking water. However, this a priori tempting solution is not possible in practice due to the local legislation on protection zones.

b) A second solution could consist in trying to cancel the effect of the drain by installing a grout curtain or a slurry wall located just upstream of the drain in order to restore the initial feeding mode of the spring. It is a very expensive solution, which, in addition, would be accompanied by many technical difficulties and uncertainties (i.e. stability of the slope and of the wall by a rise of water pressure, uncertainties about the actual rebirth of the spring). 
Although this schema is about the only solution to try to restore the spring, it seems practically infeasible.

c) Another solution consists in setting up a new collecting drain or well (in conformity with the local legislation with regards to the protection zones) upstream of the existing drain. The drilling of a well (or a series of wells, if need be) would make it possible to restore the water supply of the village with legal protection zones. However, it is clear that the drilling would be preceeded by more detailed investigations (geophysical prospection) in order to determine optimal locations.

Unfortunately, the full restoration of the natural spring appears to be one of the most technically and financially difficult option ... while it is surely the most suitable in the name of a sustainable development. 